\title{
Gingival Health Status and Dental Anomalies In Relation To Height For Age Among Children With Congenital Heart Disease
}

\author{
Dr. Nada J. Radhi, B.D.S., M.Sc., Ph.D. $\left({ }^{1}\right)$, Marwa Jamal Al-Haidary, B.D.S ( ${ }^{2)}$ \\ ${ }^{1}$ College of Dentistry/ University of Baghdad/M.Sc. Student, Department of Pedodontics and \\ Preventive Dentistry. \\ ${ }^{2}$ College of Dentistry/ University of Baghdad/ Assist. Professor, Department of Pedodontics and \\ Preventive Dentistry.
}

\begin{abstract}
:
Background: Congenital heart disease (CHD) is one of the most common developmental anomalies in children. Affected children require special care in dentistry because of their susceptibility to infective endocarditis from oral infections and at high risk to develop oral diseases.

Materials and methods: The sample involved children with congenital heart disease (Cases) consisted of 399 male and female aged between (6-12) years, attending to Ibn Al-Bitar specialized center for cardiac surgery. Control group of 485 children were examined from primary schools in Baghdad city. Modified Gingival Index (MGI) was used to assess gingival condition of participants by lobene (1986). Diagnosis of dental anomalies was assessed following criteria of WHO (1977). The assessment of nutritional status was performed using height for age following Centers for Disease Control and Prevention growth chart (3). All data were analyzed using statistical package for social science (IBMSPSS) version 23.

Results: The present study revealed that (100\%) of the total sample were affected by gingival inflammation with higher mean rank value among CHD cases than control with significant difference $(p<0.01)$. For the total sample, the mild type of gingivitis was the most distributed type, (65.7\%) for CHD cases and (99.2\%) for control group. No statistically significant differences were found between two gender $(P>0.05)$. The percentage of enamel anomalies was higher among CHD cases than control with high significant difference $(p<0.01)$. For cases, higher mean rank values of count of teeth with any anomaly were recorded among 12 years age group. Males had higher mean values than females with not significant ( $p>0.05)$. The value of gingival index according to height for age was higher among stunted cases than not stunted with statistically significant difference $(p<0.05)$. While the mean rank values of count of teeth with any anomaly were higher among not stunted cases than stunted but statistically no significant difference ( $p>0.05$ ).

Conclusion: The results of current study revealed that these children are at high risk from oral diseases. Children with congenital heart disease had high levels of gingivitis, dental anomalies and malnutrition. Keywords: CHD, dental anomalies, gingival health, nutrition.
\end{abstract}

\section{Introduction}

Congenital heart disease (CHD) is one of the most common congenital anomalies in children, with a mean incidence of approximately 8-10 cases per 1000 live births (1). The human heart develops between the 8th and the 12th gestational week, a disturbance in this process may result in an anomaly of congenital heart disease (2). It is one of the leading causes of morbidity and mortality in the first years of life (3). There are many types of congenital heart defects; they range from simple defects with no symptoms to complex defects with severe, life-threatening symptoms but the most common anomalies Ventricular Septal Defect (VSD) and Aterial Septal Defect (ASD) (4). Clinically classified depending on the existence of cyanosis. Gingivitis is an inflammatory condition of the gingiva which is almost always present in all form of gingival disease, because bacterial plaque, which causes inflammation and irritating factors which favor plaque accumulation are often present in the gingival environment (5). Mild form of gingivitis is the most common form of gingivitis in pediatric population which is the reversible form, during puberty; gingivitis may be a response to hormonal changes in the developing adolescent, though more pronounced when there is plaque accumulation (6-11). Gingival disease and other oral symptoms may occur in children with congenital heart disease, the oral changes include a purplish red discoloration of the lips and gingiva and sometimes sever marginal gingivitis and periodontal destruction.

The tongue appear coated, fissured and edematous and there is extreme reddening of the fungiform and filiform (12-14). Many studies reported that children with CHD had a higher gingival inflammatory index in comparison with control (15-17). Moreover, AL-Etabi revealed that the prevalence of gingivitis is $100 \%$ among 
children with congenital heart disease with high significant difference concerning each age and gender (18). Dental anomalies refer to disturbances during the tooth development (19). They can be congenital or acquired (20). The congenital anomalies of teeth are caused during tooth development, whereas the acquired anomalies are caused after tooth development (21). Developmental defects of enamel may be defined as disturbances in hard tissue matrices and in their mineralization during odontogensis (22). These defects have been classified according to their clinical appearance as demarcated opacity, diffuse opacity or hypoplasia (23). Enamel hypoplasia is a quantitative defect related with a decreased or altered amount of enamel (24). It could occur in form of pit (single or multiple, shallow or deep, scattered or in row arranged horizontally across the tooth surface), grooves (single or multiple, narrow or wide), partial or complete absence of enamel- over a considerable area of tooth (23). Opacity is a qualitative defect involving alteration in the translucency of the enamel with normal thickness and smoothness of its surface, occurring in two forms, demarcated and diffuse $(23,25)$. Demarcated opacities have a clear boundary with adjacent normal enamel and clinically can be white, creamy, yellow or brown. Diffuse opacities can be differentiated from demarcated one by absence of clear boundary between normal and affected enamel in the tooth $(23,26,27$,$) .$

There are limited studies concerning the enamel defects among patient with CHD in comparison to healthy populations, Hallet et al reported that the patients with congenital heart defects have increased prevalence of developmental enamel defects in comparison to control groups (28). Also El-Etabi found that the prevalence of enamel defect was higher among children with VSD (80\%) than control (20\%) (18). In contrast to the above, Franco et al found a significantly higher number of developmental enamel defects in the control group as compared to the cardiac group (29). It is a popular view that children with congenital heart disease are often small and undernourished. Malnutrition is a common cause of morbidity in children with congenital heart disease (30). Moreover, the severity of growth disturbance depend on the anatomical defect of heart and its functional defect, however, most children with mild defect grow normally but gaining weight slower than normal $(9,18,31)$.

Aims of the study: The recent study aims to identify the prevalence and severity of gingival health condition and dental anomalies in relation to nutritional status (height for age) among children with congenital heart disease in comparison to healthy controls.

\section{Materials And Methods}

The sample (cases) involved children with congenital heart disease (cases) consisted of 399 male and female aged between (6-12) years according to the last birthday (23). The patient at first diagnosed by the specialist as having different type of congenital heart disease attended to Ibn Al-Bitar specialized center for cardiac surgery for diagnosis, treatment and follow up. An approval was obtained from patient's parents before any examination. All children were examined for one time during the period of study. All children with no medication for three months ago during the time of study. The control group consisted of 485 students matching with age and gender from primary and secondary schools in Baghdad city, they are healthy without any systemic disease. The students were selected randomly by using simple random selection method depending on lists of students in each class. Modified Gingival Index (MGI) was used to assess gingival condition of participants (32). Scores ranging from 0 to 4 were employed. MGI has been used by several authors since it is based on visual inspection, eliminating the use of probing or pressure to establish the presence or absence of inflammation. Unlike the Gingival index, MGI has a noninvasive approach method, meaning there is no gentle probing to possibly provoke bleeding on pressure, which was one of the main reasons for its development. The other reason for its development was to increase sensitivity in the low region of the scoring scale. The labiallfacial and lingual surfaces of gingival margins and the interdental papillae of selected teeth (upper right second molar, upper left central incisor, upper left first molar, lower left second molar, lower right central incisor and lower right first molar) are examinated and scored. The modified developmental defect of enamel index (DDE) was used (23). Regarding dental anomalies, Enamel abnormalities were classified in to one of three types on the basis of their appearance.

They vary in their extent, position on the tooth surface and distribution within the dentition. Ten index teeth were examined on the buccal surface only, if any index tooth is missing, the area was excluded. These teeth include: $11,12,13,14,21,22,23,24,36,46$ for permanent teeth and 51, 52, 53, 54, 61, 62, 63, 64, 75, 85 for primary teeth. The buccal surface which extend from incisal edge or cuspal point to gingival, and from the mesial to the distal embrasure was inspected visually for the defect and if there was any doubt, area such as hypoplastic pits were checked with periodontal probe to confirm diagnosis, any gross plaque or food deposits were removed and the teeth were examined in wet condition. If there was any doubt about presence of an abnormality, the tooth surface was scored normal (code 0). Similarly, a tooth surface with a single abnormality less than $1 \mathrm{~mm}$ in diameter was scored normal, any abnormality that cannot be readily in to one of the three basic types was scored as other defect, if more than $2 / 3$ of the tooth surface heavily restored, badly decayed or 
fractured, was not examined. Also, Each child was examined for presence of any supernumerary teeth using either code 0 (No): which mean there was no supernumerary tooth, or 1 (Yes): which mean there was a supernumerary tooth (19), and examined for the absence of any teeth using the code 0 (No) or 1 (Yes), the students were asked if the tooth was extracted due to caries or others reasons (33). While fusion and gemination were examined in the same manner as those used for supernumerary teeth using code either 0 (No), or 1 (Yes) (34). Nutritional status was assessed by using anthropometric measurements included measurement of weight and height according to Trowbidge (35) using digital electronic balance and height measuring tape. BMI was calculated by dividing weight of each child by his/her length^2 as follow: $\mathrm{BMI}\left(\mathrm{Kg} / \mathrm{m}^{\wedge} 2\right)=\mathrm{Body}$ weight $(\mathrm{Kg}) / \mathrm{Height}^{\wedge} 2\left(\mathrm{~m}^{\wedge} 2\right)$. The values of BMI was compared according to CDC growth charts (36) according to the age and gender because unavailability of Iraqi standard for comparison.

\section{Results}

The distribution of total sample according to gender seen in table (1). This Table shows a higher percentage of females was recorded among both groups. This study revealed that all children examined were affected by gingivitis (100\%) among CHD cases and control group. Gingival index (Median and Mean rank) among CHD cases and control group is shown in Table (2). A higher value of mean rank was observed among CHD cases than the control group with higher statistical significant difference $(p<0.01)$. The median and mean rank of gingival index among CHD cases by age and gender are shown in Table (3). A higher mean rank value of gingival index was recorded among age group 8-9 years, followed by 10-11 years then age group12 years respectively with highly statistical significant difference $(p<0.01)$. Concerning gender differences, higher mean rank value of gingival index was found among females than males but statistically no significant difference was recorded ( $p>0.05)$. Regarding dental anomalies, the distribution of total sample with dental anomalies (at least one tooth with demarcated opacity, supernumerary teeth, hypodontia and at least one tooth with any anomaly) are shown in Fig. (1), while fusion/gemination were absence in this study. The percentages of dental anomalies were higher among CHD cases than control groups. Table (4) shows the distribution of CHD cases with dental anomalies (at least one tooth with demarcated opacity, supernumerary teeth, hypodontia and at least one tooth with any anomaly) by age and gender. The percentages of demarcated opacity and hypodontia were higher among age group 12 years, while the lower percentage was among age group 6-7 years with no significant differences $(p>0.05)$. While for supernumerary teeth, higher percentage was recorded among age group 6-7 years and 10-11 years than other age groups with no significant differences $(p>0.05)$. Concerning gender, the percentages were higher among females than males regarding demarcated opacity and supernumerary teeth, while the opposite results were noticed concerning hypodontia and tooth with any anomaly, all these results were statistically not significant $(\mathrm{p}>0.05)$. Regarding nutritional status, the distribution of total sample according to the nutritional status indicator (height for age) is shown in Table (5).

The percentage of stunting and severe stunting among CHD cases was higher than that among control group, while the opposite finding was recorded concerning of acceptable and unusual tall these results were statistically highly significant $(\mathrm{p}<0.01)$. The distribution of stunting among CHD cases by age and gender are seen in table (6). The higher percentage of stunting was observed among age group 12 years but the lowest percentage was observed among age group 6-7 years, this result was statistically significant $(p<0.05)$. Concerning gender, the percentage of stunting was found to be higher among females than males, however; the difference was statistically not significant ( $p>0.05$ ). Table (7) illustrates the median and mean rank of gingival index according to nutritional indicators height for age (HFA) among CHD cases. The mean rank value of gingival index was higher among stunted CHD cases than not stunted with statistically significant difference $(p<0.05)$. The distribution of CHD cases with dental anomalies (At least one tooth with demarcated opacity, supernumerary teeth, hypodontia and at least one tooth with any anomaly) according to nutritional indicator height for age (HFA) seen in Table (8). The percentage of at least one tooth with demarcated opacity and hypodontia were higher among stunted than not stunted CHD cases; while the opposite results were found for other anomaly, with no significant differences $(p>0.05)$.

\section{Discussion}

In present study the prevalence of gingival inflammation was (100\%) for the total sample. Moreover, the CHD cases had significantly higher gingivitis as compared to control group. These results are in agreement with other studies $(13,16-18,37)$. Specific reasons for this are not clear but suggested reasons include a low priority to dental care by parents/caregivers of these children. They also harbored specific HACEK microbes (Haemophilus spp, Actinobacillus actinomycetemcomitans spp, Cardiobacterium hominis, Eikenella corrodens and Kingella spp) especially, Eikenella corrodens (E.c.) and Actinobacillus actinomycetemcomitans (A.a.) within the gingival crevice to a greater extent in the CHD cases than control group (13, 16). Also this study observed that the gingival index increased with age, gingivitis tend to be more chronic and more frequent with advancing age $(38,39)$. Females showed a higher gingival index than males but the difference was not 
significant $(\mathrm{p}>0.05)$. This could be related to that the females in the present study had lower nutritional status than males. Also this study revealed that the distribution of dental anomalies were higher among CHD cases than control groups, the same results found by others $(18,28,37,40)$. These differences may be due to hypomineralization of enamel especially among acyanotic CHD cases (41). El-Hawary et al, prove that, the presence of alterations in enamel and dentin of deciduous incisors obtained from CHD patients, these changes were observed in the ultra structure as well as the mineral content $(\mathrm{Ca}$ and $\mathrm{P})$ of enamel and dentin, also, Environmental scanning electron microscope analysis of enamel showed an increase in dissolution after preparation by etching. Also the number of dissolved prism heads increased, others manifested non-uniform outlines (43). Regarding the age, the percentages of demarcated opacity and hypodontia were higher among age group 12 years with no significant differences $(p>0.05)$. The percentages of demarcated opacity and supernumerary teeth were higher among females than males with no significant differences $(\mathrm{p}>0.05)$, definitive reason for this finding is not documented but suggested to be due to females showed higher percentage of stunting than males in this study. This study found that the percentage of stunting and severe stunting among CHD cases was higher than that among control group; these results were statistically highly significant $(\mathrm{p}<0.01)$. Malnutrition in CHD can be the result of anorexia and inadequate nutrient and caloric intake, hypermetabolic state, acidemia and cation imbalance, tissue hypoxia, recurrent respiratory infections, and endocrine or genetic factors $(44,45)$. A study of Goldner et al reported that the medical condition as the size of the left to right shunt and the abnormal hemodynamic circulation is important factor in the etiology of impaired growth among children with VSD (46). Concerning age, the higher percentage of stunting was observed among age group 12 years of CHD cases, this may attributed to that the low height for age is considered an indicator of chronic under nutrition (stunting), also, the height for age indicator provides an excellent index of long tearm cumulative inadequacies of nutrition $(47,48)$. Females show higher percentage of stunting than males,

No explanation was able to be given concerning this variation though it may be attributed to $\mathrm{X}$ and $\mathrm{Y}$ Chromosome as suggested $(49,50)$. The gingival index was found to be higher among stunted than not stunted CHD cases with statistically significant difference. These differences may be attributed to the deficiency of protein which under experimental condition showed to promote the progress of periodontal disease, the permeability of the sulcular epithelium is decreased and it's deficiency negatively affect the activity of the fibroblast, as well as atrophic and degenerative changes in connective tissue of gingiva are usually seen (51). As well as the iron deficiency affect the immune system and there is some evidence to suggest that periodontal disease progresses more rapidly in undernourished populations and the important role of nutrition in maintaining an adequate host immune response may explain this observation (52-54). In the present study, the percentages of at least one tooth with demarcated opacity and hypodontia were higher among stunted CHD cases than not stunted; while regarding supernumerary tooth the opposite results were recorded. These differences were statistically not significant $(\mathrm{p}>0.05)$. Nutritional deprivation and chronic illness are important causes of enamel defects (55). Also, the deficiency of nutritional elements can affect epithelial cell function and the mineralization process, such a situation may produce a developmental setting conductive to formation of the hypoplastic defect $(56,57)$. Enamel defects result from severe cumulative events associated with external factors because they make a strong impact on health and have repercussions on the quality of life of the individual (58). Also, Al-Etbi found that the hypoplastic defects for primary teeth were found to be higher among malnourished children than well nourished regarding both VSD groups, while, for permanent teeth show higher mean values for both demarcated opacities and hypoplasia within malnourished as compared to well nourished with statistically no significant differences (18).

\section{Conclusion}

The results of current study revealed that these children are at high risk from oral diseases. Children with congenital heart disease had high levels of gingivitis, dental anomalies and malnutrition.

\section{References}

[1]. Bernier L, Stefanescu A, Samoukovic G, Tchervenkov I. The challenge of congenital heart disease worldwide: epidemiologic and demographic facts. Semin Thorac Cardiovasc Surg Pediatr Card Surg Annu. 2010; 13:26-34.

[2]. Cameron A, Widmer R. Handbook of pediatric dentistry. 3rd ed. Mosby, Elesvir, 2008.

[3]. Shah G, Singh M, Pandey T, Kalakheti B, Bhandari G. Incidence of congenital heart disease in tertiary care hospital. Kathmandu University Medical Journal, 2008; 6: 33-36.

[4]. Kliegman R, Stanton B, Schor N, Geme J and Behram R. Nelson textbook of pediatrics; 19th ed. USA, 2011.p. 1549-1600.

[5]. Malanchuk V, Borysenko A, Khomenko L, Nespriadko V, Ostapko O, Kulbashna Y, Kolenko Y, Zhegulovich Z. Oral and maxillofacial surgery. Part 1. Vinnytsia, Nova Knyha Publisher, 2011.

[6]. Diab BS. Nutritional status in relation to oral health condition among 6-10 years primary school children in middle region of Iraq. PhD thesis submitted to the College of Dentistry, University of Baghdad, 2003.

[7]. Radhi J. Oral health status in relation to nutritional analysis and salivary constituents among a group of children with Downes Syndrome, in comparison to normal children. Ph.D. Thesis, College of Dentistry, University of Baghdad, 2009.

[8]. McDonald C, Debnath M, Doyle M, Langan C, Leonard B, Cannon M. Recent advances in psychoneuroimmunology: Inflammation in psychiatric disorders. Translat Neurosci, 2011; 2(2):121-37. 
[9]. Al-Saidy A. The Periodontal health status among patients attending the periodontal department, School of Dentistry, Facualty of Medical Science, Sulaimani University, Kurdistan Region, Iraq. Diyala Journal of Medicine, 2013; 4(1):1-14.

[10]. Khiala H. Depression status in relation to oral health condition and salivary physiochemical characteristics among 15 years old school students in AL-Swera City-Wassit Governorate-Iraq. Master Thesis. Collage of dentistry, University of Baghdad, 2014.

[11]. Abdul-Ameer A. Stressful life events in relation to oral health condition and selected salivary constituents among 17-18 years old secondary school students in Baghdad City/Iraq. Master Thesis, College of Dentistry, University of Baghdad, 2015.

[12]. Carranza F. Gingival disease in children: Carranza clinical periodontology. 9th ed. W. B. Saunders Company. Philadephia, 2002.

[13]. Steelman R, Rosen A, Nelson R, Kenamond A. Gingival colonization with selective HACEK microbes in children with congenital heart disease. Clin oral Invest, 2003; 7:38-40.

[14]. Scully C, Cawson R. Medical problems in dentistry. 5th ed. Churchill, livingstone, London, 2005.

[15]. Saunders C and Roberts G. Dental attitudes, knowledge, and health practices of parents of children with congenital heart disease. Arch Dis Child, 1997; 76:539-540.

[16]. Steelman R, Einzig S, Balian A, Thomas J, Rosen D, Gustafson R, Gochenour L. Increase susceptibility to gingival colonization by specific HACEK microbes in children with congenital heart disease . Journal of Pediatric Dentistry 2008; 25(1):91-94.

[17]. Rai K, Supriya S, Hegde M. Oral health status of children with congenital heartdisease and the awareness, attitude and knowledge of their parents. J Clin Pediatr Dent. 2009; 33:315-8.

[18]. AL-Etbi N. Enamel defects in relation to nutritional status among a group of children with congenital heart disease (Ventricular septal defect). J BaghColl Dentistry. 2010; 23(3):124-129.

[19]. Neville W, Damm D, Allen M, Bouquot J. Oral and maxillofacial pathology. 3rd ed. St. Louis: Saunders; 2009.

[20]. Garant PR. Early Tooth development. In: Garant PR, editor. Oral cells and tissues. Chicago: Quintessence; 2003; p. 1-23.

[21]. White C, Pharoah J. Oral radiology: principles and interpretation. 6th ed. St. Louis: Mosby Elsevier; 2009.

[22]. Wong M, McGrath C and King M. Dental practitioners views on the need to treat developmental defects of enamel. Community Dent Oral Epidemiol. 2007; 35:130-139.

[23]. World Health Organization (WHO). Oral Health Survey, basic methods. Geneva, Switzerland, 1997.

[24]. Martínez Gómez P, Guinot Jimeno F, Bellet Dalmau J, Giner Tarrida L. Prevalence of molar-incisor hypomineralisation observed using transillumination in a group of children from Barcelona (Spain). International Journal of Paediatric Dentistry 2012; 22:100109.

[25]. Dean H. The investigation of physiological effects by the epidemiological method. In: Moulton FR, editor. Fluorine and dental health. American Association for the Advancement of science, Washington DC, 1982.

[26]. FDI (Federation Dentaire International). An Epidemiological index of the developmental defects of enamel index (DDE Index). Int Dent J 1982; 32:159-167.

[27]. FDI (Federation Dentaire International Working Group) : A review of developmental defects of the enamel dental index (DDE Index). Commission on Oral Health, Research and Epidemiology. Int Dent J 1992; 42(6):411-426.

[28]. Hallett B, Radford J and Seow M. Oral health of children with congenital cardiac diseases: a controlled study. Ped Dent 1992; 14 (4):224-230.

[29]. Franco E, Saunders P, Roberts J, Suwanprasit A. Dental disease, caries related microflora and salivary IgA of children with severe congenital cardiac disease: an epidemiological and oral microbial survey. Pediatr Dent. 1996; 18(3):228-235.

[30]. Peterson E, Wetzel T. Growth failure in congenital heart disease: where are we now? Curr Opin Cardiol 2004;19:81- 83.

[31]. Webb G. Smallhorn J. Therrien J. Redington A. Disease of the heart, Pericardium, and Pulmonary Vasculare Bed: Braunwald heart disease. 8th ed. Saunders Elsevie, 2008.

[32]. Lobene R, Weatherford T, Ross M, Lamm A, Menaker L. A modified gingival index for use in clinical trials. Clin Prev Dent, 1986; 8(1):3-6.

[33]. El-Mahdi L, Hashim M, Ali S. Parental knowledge of their children's congenital heart disease and its impact on their growth. Khartoum J 2009; 2(2): 191-196.

[34]. Fekonja A. "Hypodontia in orthodontically treated children". European Journal of Orthodontics. 2005; 27(5):457-60.

[35]. Joshi V, Pavankumar K, Ramana V, Joshi S, Saritha M. Bilateral Fusion of the Mandibular Primary Incisors: A Case Report. International Journal of Oral and Maxillofacial Pathology, 2011; 2(2):40-43.

[36]. CDC growth Charts. Unit state. National Center for health statistics in collaboration with the National Center for Chronic Disease Prevention and Health Promotion, 30 may 2000.

[37]. Trowbridge L. Evaluating nutritional status of infant and children. In : paige DM. Clinical nutrition, 2nd ed. Mosby, St, Louis, Washington DC Toronto 1988; 119-136.

[38]. Hugoson A, Koch G, Rylander H. Prevalence and distribution of gingivitis-periodontitis in children and adolescents. Swed Dent J 1981; 5:91-103.

[39]. Zafar S. Yasin S. Siddiqi A. Naz F. Oral health status of paediatric cardiac patients: Acase_control study. International Dentistry Sa. 2008; 10:6.

[40]. Marya A. Textbook of public health dentistry.1st ed. Jaypee Brothers, New Delhi, 2011.

[41]. Tasioula V, Balmer R, Parsons J. Dental health and treatment in a group of children with congenital heart disease. Pediator Dent 2008; 30(4):323-328.

[42]. Mahoney P: Incremental enamel development in modern human deciduous anterior teeth. Am J Phys Anthropol. 2012; $147(4)$ :637651. 43. EL-Hawary Y. EL-Sayed B. AL-Hakem G. Ibrahim F. Deciduous teeth structure changes in congenital heart disease: Ultrastructure and microanalysis Interventional Medicine and Applied Science, 2014; 6 (3):111-117.

[43]. Friedman F, Silverman N. Congenital heart disease in infancy and childhood. In: Braunwald E, Zipes DP, Libby P, eds. Heart disease: A textbook of cardiovascular medicine. 6th ed. Philadelphia: Saunders, 2001. p. 1505-14.

[44]. Devi S. Jani R. Review on nutritional management of cardiac disorder in Canines. Veterinary World. 2009; 2(12):482-485.

[45]. Goldner M. Martins M. Mendes A. Craniofacial characteristics of patients with heart disease. Am J Orthod Detofacial Orthop. 2009; 136(4):554-8.

[46]. Gorestein J. Assessment of nutritional status: Effect of different method to determine age or the classification of under nutrition. Bulletin of the WHO. 1989; 67(2):143-150.

[47]. Gorestein J, Sullivan K, Yip R, De Onis M, Trowbridge F, Fajans P, Clugston G. Issues in the assessment of nutrition status using anthropometry. Bull WHO. 1994; 72(2):273-83.

[48]. Gatta E. Primary teeth emergency and enamel anomalies in relation to nutritional status among 4-48 months old children in Baghdad City, Iraq. Master Thesis, College of Dentistry, University of Baghdad, 2005.

[49]. Hassan Z. Nutritional status and dental caries in five years-old kindergarten children of Baghdad city. Journal of Faculty of Medicine, Baghdad 2006; 48(2):172-176. 
[50]. Nizel E, Papas S. Nutrition in clinical dentistry. 3rd ed. W.B. Saunders Company, 1989.

[51]. Insel P, Turner E, Ross D. Disconering nutrition. Jones and Bartlett Publishers, USA. 2003; PP: 11-27; 33-57; 379-423.

[52]. WHO/FAO. Diet, nutrition and the prevention of chronic diseases. WHO Technical Report Series, 916. WHO, Geneva, 2003.

[53]. Nanism M. Clinical characteristics and pathophysiologic features of growth restriction, insulin resistance and tumour development. Academic Dissertation. University of Helsinki. 2009.

[54]. Li Y, Navia M, Bian Y. Prevalence and distribution of developmental enamel defects in primary dentition of Chinese children 3-5 years old. Community Dent Oral Epidemiol 1995; 23:72-79.

[55]. Seow W. Enamel hypoplasia in the primary dentition. ASDCJ Dent Child. 1991; 58:441-542.

[56]. Luckas J. Walimbe S. Floyed B. Epidemiology, enamel hypoplasia in deciduous teeth: Explaining variation in prevalence in Western India. Am J Human Biol. 2001; 13:788-807.

[57]. Cruvinel R, Gravina B, Azevedo D, Bezerra C, Toledo O. Prevalence of dental caries and caries-related risk factors in premature and term children. Braz Oral Res. 2010; 24(3):329-35.

Table 1: The distribution of total sample by gender.

\begin{tabular}{|c|c|c|c|c|c|c|}
\hline \multirow{3}{*}{ Groups } & \multicolumn{9}{|c|}{ Gender } \\
\cline { 2 - 8 } & \multicolumn{2}{|c|}{ Male } & \multicolumn{2}{c|}{ Female } & \multicolumn{2}{c|}{ Total } \\
\cline { 2 - 8 } & No. & $\%$ & No. & $\%$ & No. & $\%$ \\
\hline CHD cases & 175 & 43.9 & 224 & 56.1 & 399 & 100.0 \\
\hline Control group & 224 & 46.2 & 261 & 53.8 & 485 & 100.0 \\
\hline
\end{tabular}

Table 2: Gingival index (Median and Mean rank) among CHD cases and control group.

\begin{tabular}{|l|c|c|c|c|c||}
\hline \multicolumn{3}{|c|}{ CHD cases } & \multicolumn{3}{c|}{ Control group } \\
\hline No. & Median & Mean rank & No. & Median & Mean rank \\
\hline 399 & 2 & 639.5 & 485 & 1 & 280.4 \\
\hline
\end{tabular}

Table 3: The median and mean rank of gingival inder among $C$ HD cases by age (years) and gender.

\begin{tabular}{|c|c|c|c|}
\hline \multirow{2}{*}{ Age and Gender } & \multicolumn{3}{|c|}{ CHD cases } \\
\cline { 2 - 4 } & No & Median & Mean rank \\
\hline $6-7$ & 172 & 1.8 & 177.8 \\
\hline $8-9$ & 69 & 2.7 & 229.1 \\
\hline $10-11$ & 81 & 2 & 215.1 \\
\hline 12 & 77 & 2 & 207.5 \\
\hline Males & 175 & 2 & 198.2 \\
\hline Females & 224 & 2 & 201.4 \\
\hline
\end{tabular}

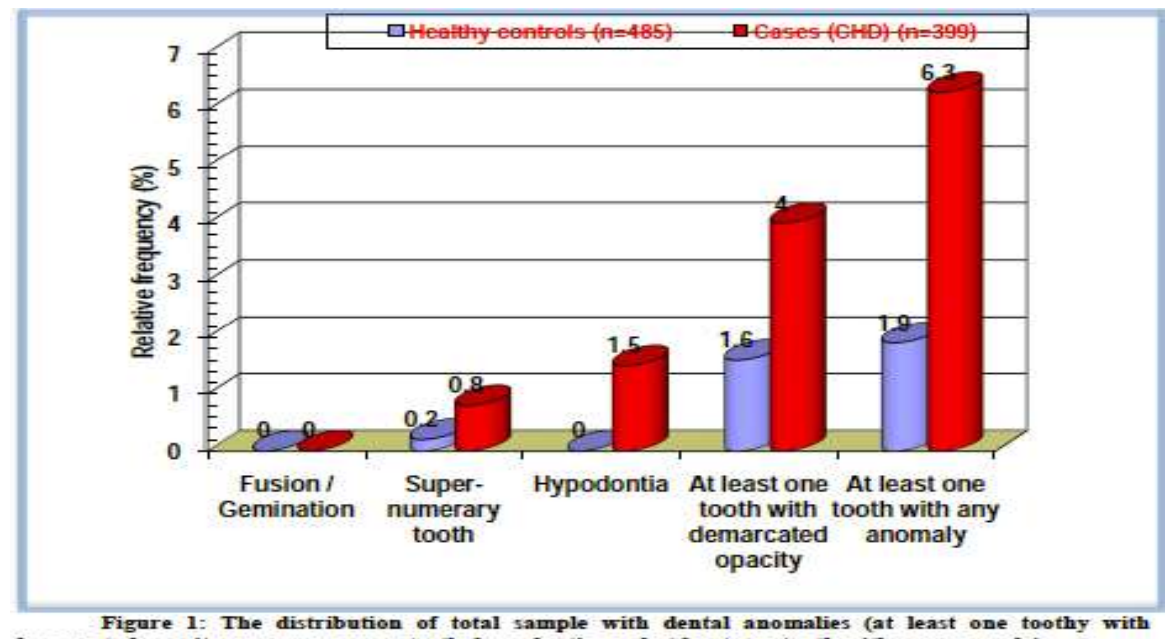

Figure 1: The distribution of total sample with dental anomalies (at least one too
demarcated opacity, supernumerary teeth, hypodontia, and at least one tooth with any anomaly). 
Table 4: The distribution of CHD cases with dental anomalies (at least one tooth with demarcated opacity, supernumerary teeth, hypodontia and at least one tooth with any anomaly) by age (years) and gender.

\begin{tabular}{|c|c|c|c|c|c|c|c|c|c|}
\hline \multirow{3}{*}{$\begin{array}{l}\text { Age and } \\
\text { Gender }\end{array}$} & & \multicolumn{8}{|c|}{ (CHD) cases } \\
\hline & \multirow{2}{*}{ Total } & \multicolumn{2}{|c|}{$\begin{array}{l}\text { At least one tooth with } \\
\text { demarcated opacity }\end{array}$} & \multicolumn{2}{|c|}{ Supernumerary teeth } & \multicolumn{2}{|c|}{ Hypodontia } & \multicolumn{2}{|c|}{$\begin{array}{l}\text { at least one tooth with } \\
\text { any anomaly }\end{array}$} \\
\hline & & No. & $\%$ & No. & $\%$ & No. & $\%$ & No. & $\%$ \\
\hline $6-7$ & 172 & 3 & 1.7 & 2 & 1.2 & 0 & 0.0 & 6 & 3.5 \\
\hline $8-9$ & 69 & 5 & 7.2 & 0 & 0.0 & 1 & 1.4 & 5 & 7.2 \\
\hline $10-11$ & 81 & 2 & 2.5 & 1 & 1.2 & 2 & 2.5 & 5 & 6.2 \\
\hline 12 & 77 & 6 & 7.8 & 0 & 0.0 & 3 & 3.9 & 9 & 11.7 \\
\hline Males & 175 & 7 & 4.0 & 1 & 0.6 & 4 & 2.3 & 12 & 6.9 \\
\hline Females & 224 & 9 & 4.0 & 2 & 0.9 & 2 & 0.9 & 13 & 5.8 \\
\hline
\end{tabular}

Table 5: The distribution of total sample according to nutritional indicator status Height for age

\begin{tabular}{|c|c|c|c|c|}
\hline \multirow{2}{*}{$\begin{array}{c}\text { Height for age } \\
\text { Categories }\end{array}$} & \multicolumn{2}{|c|}{ CHD cases } & Control group \\
\cline { 2 - 5 } & No. & $9 \%$ & No. & $\%$ \\
\hline Severe stunting & 39 & 9.8 & 0 & 0.0 \\
\hline Stunting & 58 & 14.5 & 6 & 1.2 \\
\hline Acceptable & 301 & 75.4 & 453 & 93.4 \\
\hline Unusual tall & 1 & 0.3 & 26 & 5.4 \\
\hline Total & 399 & 100 & 485 & 100 \\
\hline
\end{tabular}

Table 6: The distribution of stunting among $\mathrm{CHD}$ cases by age (years) and gender.

\begin{tabular}{|c|c|c|c|}
\hline \multirow{2}{*}{$\begin{array}{c}\text { Age and } \\
\text { Gender }\end{array}$} & \multicolumn{3}{|c|}{ (CHD) cases } \\
\cline { 2 - 4 } & \multirow{2}{*}{ Total } & No. & $\%$ \\
\cline { 2 - 4 } & 172 & 33 & 19.2 \\
\hline $6-7$ & 69 & 15 & 21.7 \\
\hline $8-9$ & 81 & 21 & 25.9 \\
\hline $10-11$ & 77 & 28 & 36.3 \\
\hline 12 & 175 & 40 & 22.9 \\
\hline Male & 224 & 57 & 25.4 \\
\hline Female & & & \\
\hline
\end{tabular}

Table 7: The median and mean rank of gingival inder according to nutritional indicators height for age (HFA) among CHD cases group.

\begin{tabular}{|l|c|c|c|c|c|}
\hline \multicolumn{3}{|c|}{ HFA } \\
\hline \multicolumn{3}{|c|}{ Not stumted } & \multicolumn{4}{c|}{ Stunted } \\
\hline No. & Median & Mean rank & No. & Median & Mean rank \\
\hline 302 & 2 & 194.1 & 97 & 2 & 218.3 \\
\hline
\end{tabular}

Table 8: The distribution of dental anomalies (at least one tooth with demarcated opacity, Supernumerary teeth, hypodontia and at least one tooth with any anomaly) according to nutritional indicators height for

\begin{tabular}{|c|c|c|c|c|c|c|}
\hline \multirow{3}{*}{ Dental anomalies } & \multicolumn{6}{|c|}{ HFA } \\
\hline & \multirow[b]{2}{*}{ No. } & \multicolumn{2}{|c|}{ Not stunted } & \multirow[b]{2}{*}{ No. } & \multicolumn{2}{|c|}{ Stunted } \\
\hline & & No. & 96 & & No. & $\%$ \\
\hline At least one tooth with demarcated opacity & \multirow{4}{*}{302} & 12 & 4.0 & \multirow{4}{*}{97} & 4 & 4.1 \\
\hline Supernumerary tooth & & 3 & 1.0 & & 0 & 0.0 \\
\hline Hypodontia & & 4 & 1.3 & & 2 & 2.1 \\
\hline At least one tooth with any anomaly & & 19 & 6.3 & & 6 & 6.2 \\
\hline
\end{tabular}

